\title{
ASPECTOS SOBRE CRIANÇAS COM TRANSTORNO DO DEFICIT DE ATENÇÃO COM HIPERATIVIDADE (TDAH)
}

Patrícia de SOUZA ${ }^{1}$

Gleicione Aparecida Dias Bagne de SOUZA ${ }^{2}$

Recebido em: 05/10/2015 - Aprovado em: 15/04/2016 - Disponibilizado em: 30/07/2016

\begin{abstract}
Resumo
O presente artigo aborda os aspectos gerais sobre o TDAH (transtorno do déficit de atenção com hiperatividade). Tratar-se-á as causas, os sintomas, os diagnósticos, os tratamentos e as intervenções da família, da escola, das áreas médicas e da Psicopedagogia. |O TDAH é um distúrbio que atinge crianças já na primeira infância e na maioria dos casos permanece quando adultos. É importante que frente aos sintomas, se faça um minucioso diagnóstico e em seguida um tratamento adequado.
\end{abstract}

Palavras- chave: Hiperatividade. Distúrbio. Atenção.

\begin{abstract}
This article discusses the general aspects of the ADHD (attention deficit of the disorder with hyperactivity). This will be the causes, symptoms, diagnoses, treatments and interventions of the family, school, the medical areas and the psichopedagogy. The ADHD is a disorder that affects children already in early childhood and in most cases remains when adults. It is important that symptoms are due to make a thorough diagnosis and appropriate treatment.
\end{abstract}

Keywords: Hyperacitivity. Disorder. Attention.

\footnotetext{
${ }^{1}$ Graduada em Pedagogia e Pós-graduada em Psicopedagogia Institucional do Centro Universitário do Sul de Minas.

${ }^{2}$ Graduada em Pedagogia, Mestre em Engenharia de Produção com ênfase em Mídia e Conhecimento pela Universidade Federal de Santa Catarina e Doutora em Educação pela Universidade do Minho- Portugal. 


\section{Introdução}

O Transtorno do Déficit de Atenção com Hiperatividade (TDAH) é um distúrbio bio-psicossocial, isto é, parece haver fortes fatores biológicos, sociais, genéticos e vivenciais que contribuem para a intensidade desse transtorno. Nos anos 60, devido à dificuldade de comprovação, sua definição adquiriu uma perspectiva mais funcional, tendo como sintoma primordial a atividade motora excessiva e caracterizando-se como uma síndrome de conduta.

O TDAH é caracterizado por uma série de problemas, sinais claros e repetitivos de desatenção, inquietude e impulsividade, mesmo quando a criança tenta não mostrá-lo. Esses problemas resultam de um desenvolvimento não adequado e causam dificuldades no dia-a-dia.

O Transtorno do Déficit de Atenção com Hiperatividade é responsável pela enorme frustração que os pais e filhos portadores desse distúrbio experimentam a cada dia. Adultos, adolescente e crianças, hoje diagnosticados com TDAH são frequentemente rotulados de "problemáticos", "desmotivados", "avoados", "malcriados", "indisciplinados", "irresponsáveis" ou, até mesmo, "pouco inteligentes", mas na verdade o indivíduo que tem TDAH é inteligente, criativo e intuitivo, embora não consegue realizar todo seu potencial em função desse transtorno. O Transtorno do Déficit de
Atenção com Hiperatividade tem três características principais: a desatenção, a impulsividade e a hiperatividade. Quando se lê e ouve sobre o assunto, na maioria das vezes, temos uma conotação negativa e a razão disso é o fato deste transtorno continuar sendo pouco conhecido, apesar dos estudos a respeito terem se intensificado nas últimas décadas.

Há algum tempo, pensava-se que os sintomas do TDAH diminuíam com a adolescência. Foi comprovado que o Transtorno do Déficit de Atenção com Hiperatividade atinge de $3 \%$ a $5 \%$ da população durante toda a vida. Ele nasce com o indivíduo, aparece já na pequena infância e acompanha o indivíduo durante sua vida. Pesquisas mostraram que a maioria das crianças com TDAH chega à maturidade com um padrão de problemas muito similar aos da infância e que quando adultos experimentam dificuldades no trabalho, na sociedade e familiar.

Conflitos familiares, escolares, comportamentais e psicológicos vividos por pessoas com TDAH podem ser reduzidos com diagnóstico precoce e tratamento adequado. Um grande número dos problemas, como repetência escolar e abandono dos estudos, depressão, distúrbios de comportamento, problemas vocacionais e de relacionamento, podem ser adequadamente tratados ou, até mesmo, evitados. 
Interferência do TDAH na vida do indivíduo

\section{O Transtorno do Déficit de Atenção} com Hiperatividade interfere na habilidade do indivíduo. Ele apresenta dificuldades em sustentar a atenção, de controlar as emoções, o nível de atividade, e talvez o mais importante, na habilidade de controle e inibição. $\mathrm{O}$ sinal característico da hiperatividade é a dificuldade ou inabilidade de se manter quieto e calmo, com intensa agitação motora, mesmo em situações consideradas inapropriadas. A impulsividade se manifesta pela dificuldade do indivíduo em planejar os comportamentos e as ideias, agindo de forma precipitada e impensada, frequentemente tem dificuldades para manter a atenção em tarefas, parece não estar ouvindo quando lhe é falado diretamente, tem dificuldade para ter atenção a detalhes, engana-se por descuido em tarefas e atividades, tendo assim dificuldades em organizá-las.

As características do TDAH aparecem bem cedo para a maioria das pessoas, logo na primeira infância.

De acordo com Lucy Santos (2006, p.2), existem três tipos de TDAH:

TDAH, Tipo Predominantemente Desatento

O indivíduo apresenta uma dificuldade de manter a atenção e em seguir instruções, é inquieto, desvia facilmente a atenção do que está fazendo e comete erros por prestar pouca atenção a detalhes. Dificuldade de concentração em palestras, aulas, leituras de livros, relutância em iniciar tarefas que exijam longo esforço mental, dificuldade em organizar-se com objetos.

TDAH, Tipo Predominantemente Hiperativo-Impulsivo

Este quadro de TDAH é caracterizado por crianças que se mostram mais agressivas e, dessa forma, freqüentemente são rejeitadas pelo seu grupo, pois na maioria das vezes agem sem pensar, não conseguem prever as consequiências de seus atos, e são socialmente inadequadas. Instabilidade de humor, dificuldade de seguir regras ou normas pré- estabelecidas.

TDAH, Tipo Combinado

Este quadro de TDAH é caracterizado pela pessoa que apresenta tanto os sintomas de desatenção, como os sintomas de hiperatividade e impulsividade.

Temos então, três grupos de Transtorno do Déficit de Atenção com Hiperatividade. O primeiro grupo apresenta apenas desatenção, outro hiperatividade/impulsividade e o terceiro apresentam ambos, desatenção e hiperatividade /impulsividade. É muito importante se ter em mente que um "certo grau" de desatenção e hiperatividade ocorre normalmente nas pessoas, e nem por isso elas têm o transtorno.

Para se ter esse diagnóstico e dizer se a pessoa realmente tem esse transtorno, a desatenção e/ou a hiperatividade é preciso ocorrer de tal forma a interferir no relacionamento social do indivíduo, na sua vida escolar ou no seu trabalho e os sintomas têm que ocorrer tanto na escola (ou no 
trabalho, no caso de adultos) como em casa. "É necessário que a desatenção e/ou hiperatividade causem prejuízos na vida da criança ou do adolescente para se pensar em TDAH”. (ROHDE; BENCZIK , p. 43).

\section{Causa do TDAH}

Estudos ainda não foram suficientes para precisar as reais causas do transtorno, porém a influência de fatores genéticos e ambientais já foram divulgados e bastante aceitos no meio científico. Estudos estruturais e metabólicos, somados a estudos genéticos e sobre a família, demonstram claramente que o Transtorno do Déficit de Atenção com Hiperatividade é um transtorno neurobiológico. A genética é o fator básico na determinação do aparecimento dos sintomas do TDAH, apesar do problema variar de acordo com suas experiências de vida.

Fatores genéticos não são os únicos responsáveis pelo TDAH, apesar da sua grande contribuição. Fatores ambientais e psicossociais que atuam na adaptação e na saúde emocional da criança, como por exemplo, problemas graves na relação familiar, pais com transtornos mentais, ou baixo nível sócio-econômico e cultural da família, contribuem para o desenvolvimento e manutenção de um quadro de Transtorno do Déficit de Atenção com Hiperatividade. Estudos têm afirmado que as dificuldades no contexto familiar são as consequências e não o agente etiológico do TDAH.

\section{Diagnóstico do TDAH}

O diagnóstico do Transtorno do Déficit de Atenção com Hiperatividade é realizado a partir de exame clínico, no qual são analisadas características comportamentais, relacionadas à presença ou não de hiperatividade, impulsividade e distratibilidade.

Esse diagnóstico é um processo de múltiplas facetas, ele é multi-profissional e requer participação de professores, psicólogos, médicos e se, necessário, outros profissionais da área da saúde e da educação. A participação desses profissionais, além da família, é essencial para colher adequadamente um histórico detalhado e para a correta avaliação do quadro.

Problemas biológicos e psicológicos podem contribuir para a manifestação de sintomas similares apresentados por pessoas com Transtorno do Déficit de Atenção com Hiperatividade.

Para se ter o diagnóstico do TDAH é necessário segundo Lucy Santos (2006, p.4):

\footnotetext{
Pelo menos seis sintomas de desatenção e/ou hiperatividade devem estar presentes.

É importante considerar a duração dos sintomas e a frequência dos mesmos.

Considerar o grau de prejuízos dos sintomas.
} 
A avaliação diagnóstica deve envolver os pais, a criança, a escola e o médico.

Não se pode deixar de considerar e avaliar outras causas para o problema, assim, é preciso estar atento à presença de distúrbios concomitantes.

A avaliação do TDAH inclui um levantamento do funcionamento intelectual, acadêmico, social e emocional. E um aspecto importante no diagnóstico é o cuidadoso histórico clínico de desenvolvimento, principalmente se o Transtorno do Déficit de Atenção com Hiperatividade persistir na idade adulta.

À medida que aumenta o reconhecimento de que o transtorno é permanente durante a vida da pessoa, os métodos e questionários relacionados com o diagnóstico de um adulto com TDAH são padronizados e cada vez mais acessíveis.

\section{Tratamento para pessoas portadoras do TDAH}

O tratamento de pessoas com Transtorno do Déficit de Atenção com Hiperatividade envolve e exige um esforço coordenado entre os vários profissionais das áreas médicas e pedagógicas.

Por ser uma doença com grande impacto em diversas facetas da vida dos afeados, dos familiares e da sociedade, mas, principalmente na vida escolar dessas crianças e adolescente, torna-se imperativo que sua avaliação e terapia sejam feitas por uma equipe interdisciplinar. (CAMPOS et al, 2002, p.219)

É importante a orientação aos pais e professores, além de técnicas específicas que são ensinadas ao portador. A medicação é parte importante do tratamento, pois sem ela a criança não consegue prestar atenção, se dedicar e ouvir, o que é essencial para que os outros tratamentos funcionem.

\section{O tratamento do Transtorno do Déficit} de Atenção com Hiperatividade envolve também o aprendizado de novas habilidades e o treinamento comportamental. Pessoas com TDAH devem aprender a lidar com situações altamente estimulantes, que as distraem e superexcitam. Devem aprender a estudar em lugares silenciosos e fazer pausas frequentes. $\mathrm{Na}$ sala de aula elas trabalham melhor em carteiras individuais, do que em mesas coletivas.

\footnotetext{
Para cada caso deve ser avaliado o que deve ser mudado sob orientação do médico e da equipe de acompanhamento. O membro da família que tem TDA (criança, adolescente ou adulto) e geral não cumpre suas obrigações escolares, não respeita os horários das refeições nem de dormir, de chegada à casa, não compartilha com a família, mantém suas coisas em desordem, etc. Frequentemente vive de castigo, o que torna ainda mais desafiante, menos cooperador, mais isolado da família. (CONDEMARÍN et al, 2006, p. 186)
}

É natural que os pais de crianças com Transtorno do Déficit de Atenção com

Hiperatividade se sintam frustrados e sós, pois 
esse distúrbio põe à prova os mais altos limites da paciência. A criança geralmente viola as regras, negligencia tarefas domésticas, opõem-se as tarefas de casa e definitivamente perturbam a paz criando uma situação de estresse familiar o que é necessário se trabalhar com o grupo familiar para que esses transtornos se tornem menores e mais fáceis de serem trabalhados.

É importante que a criança saiba que ela não está sendo reprimida, mas, sim, o comportamento dela, levando em consideração a quantidade excessiva de atividades para que não sobrecarreguem, e assim junto com os demais profissionais buscando um meio termo, sendo importante focalizar pontos fortes e buscar o que é melhor para a criança.

Para o sucesso dessa criança é vital que ela saiba o que existe de certo com ela e não o que está errado. Focalizando pontos fortes através de uma boa relação de pais e filhos.

\section{Influência da Escola}

$\mathrm{Na}$ escola professores devem ter disposição e flexibilidade para ajudar os alunos com TDAH a contornar o problema. Muitos professores, infelizmente, não estão atualizados quanto ao conhecimento do transtorno e seu controle. O professor quando bem orientado certamente será capaz de estabelecer várias adaptações na escola (em sala de aula) favorecendo o desempenho de seus alunos.

O ponto de partida e o melhor a fazer é informar sobre o transtorno e se atualizar constantemente, mantendo um diálogo constante com os profissionais envolvidos no caso de cada criança.

"Mantenha o esquema de trabalho o mais constante e previsível. Estas crianças precisam do ambiente para estruturar externamente o que elas têm dificuldade de estruturar interiormente." (ROHDE; BENCZIK, 1999, p. 86)

Uma sala de aula eficiente para crianças desatentas deve ser organizada e estruturada, com regras claras, programa previsível e carteiras separadas.

"As crianças e adolescentes com o transtorno apresentam dificuldades importantes de manter a atenção focalizada em um único estímulo, principalmente em ambientes não-estruturados." (ROHDE; BENCZIK, 1999, p. 88)

Para ajudar a manter o interesse da criança, otimizando a atenção e concentração do TDAH o professor deve mudar os estilos de apresentação das aulas, tarefas e materiais. Deve evitar aulas repetitivas e ter uma dose extra de paciência. Planejamento e organização devem ser ensinados a todo o momento, pois são particularmente difíceis para portadores de TDAH. Combinar aulas com momentos breves de exercício físico na sala de aula também pode ser útil. E não se 
deve esquecer uma regra importante: elogiar o aluno quando ele conseguir comportar bem ou quando ele realizar uma tarefa difícil. É importante valorizar pequenos passos alcançados, até mesmo para estimulá-los.

Desenvolver um repertório de intervenções para poder atuar eficientemente no ambiente da sala de aula de uma criança com Transtorno do Déficit de Atenção com Hiperatividade, visando minimizar o impacto negativo do temperamento da criança.

Quando estratégicas punitivas se fizerem necessárias, explique claramente para a criança a razão da advertência ou exclusão. Faça isso de modo imediato e não muito tempo após ela ter apresentado o comportamento indesejado. É fundamental para estas crianças o estabelecimento d conexão causa - efeito. (ROHDE; BENCZIK, 1999, p.89)

Sendo assim, quando surgir dificuldades, uma boa opção é pedir a ajuda e a intervenção do psicólogo ou médico, de forma que as dificuldades vão sendo superadas e o trabalho feito na escola complementa o que é realizado no consultório.

\section{Intervenção Psicopedagógica}

A combinação de tratamentos oferecidos por diversas áreas é denominada de intervenção multidisciplinar. É importante a intervenção psicológica e psicopedagógica no
A intervenção psicopedagógica junto às pessoas com Transtorno do Déficit de Atenção com Hiperatividade não se opõe à utilização de medicamentos, no intuito de contribuir para sanar a patologia do aprender e quando estes são necessários, é uma ação integradora do sujeito que é constituído por corpo, organismo, desejo e inteligência.

“A avaliação psicopedagógica constitui uma importante ferramenta no momento e determinar a forma e a intensidade em que o TDAH afeta o desempenho escolar da criança, em termos do seu rendimento." (CONDEMARÍN et al, 2006, p. 60)

No diagnóstico de uma pessoa com Transtorno do Déficit de Atenção com Hiperatividade a psicopedagogia assume um papel importante. O acompanhamento visa criar condições para que a criança retenha a sua atenção e concentração durante suas atividades, assim como estímulo para organizar-se. No lúdico, observa-se limites, interação com o meio, raciocínio matemático entre outros.

A avaliação psicopedagógica tem um papel central no diagnóstico da criança com TDAH, já que é no colégio que o problema tem maior expressão. Por outro lado, os psicopedagogos necessitam determinar com precisão quais são os processos cognitivos mais deficitários, para poder traçar planos de reabilitação ajustados às necessidades de cada criança em particular.( CONDEMARÍN et al, 2006, p. 186) TDAH. 
A intervenção Psicopedagógica deve ser realizada junto aos pais e à escola. Os pais, geralmente trazem no histórico da criança dificuldades de relacionamento, problemas comportamentais e inclusive, um desgaste familiar. Quanto à escola, a intervenção ocorre junto aos coordenadores e professores com o objetivo de levantar dados na rotina escolar do aluno, como seu rendimento nas disciplinas, organização, interesse, comportamento em sala de aula e em outras atividades em que participa e também, o seu relacionamento com colegas e professores.

"Muitas dessas crianças e muitos desses adolescentes produzem um problema de aprendizagem como mensagem inconsciente que quer ser escutada. É nessa escuta que deve incluir-se o psicopedagogo." (FERNÁNDEZ, 2001, p. 33).

É através desse pedido de socorro que a criança mostra que esta precisando de ajuda, e onde a intervenção psicopedagógica se faz presente, isto é, ela vai fazer essa escuta e assim poder intervir e chegar ao problema.

A Psicopedagogia assume o papel de orientar o comportamento e atitudes da família e da escola que colaborarão com o tratamento do indivíduo com TDAH. E o psicopedagogo com uma postura integrativa levará em conta não só o sintoma fruto de um distúrbio orgânico, mas também o afetivo e o emocional que o acompanham.

\section{Considerações finais}

Nós seres humanos somos bastantes diferentes uns dos outros e muito complexos. Uma criança, um pré-adolescente ou um adulto apresenta diferentes comportamentos conforme o ambiente e a situação em que se encontra.

O Transtorno do Déficit de Atenção com Hiperatividade (TDAH) é um transtorno neurobiológico, de causas genéticas, que aparece na infância e freqüentemente acompanha o indivíduo por toda a sua vida. A pessoa com TDAH apresenta uma predominância de um dos três principais grupos de sintomas ou uma combinação deles: Hiperatividade, Impulsividade, Distração.

Uma avaliação sistemática de comorbidades auxilia a correta orientação da família e da escola quanto aos problemas e intervenções.

Indisciplina, agressividade, inquietação e mau-humor são sintomas que podem indicar problemas psicológicos de crianças e adolescentes. Muitas vezes um aluno "excessivamente agitado" não se apresenta assim em todos os ambientes e é bastante comum que surjam queixas realizadas por professores de uma escola e que não apresentam respaldo de todos os educadores da entidade. Por isso é muito importante avaliar se o fator que faz com que a falta de atenção e o comportamento 
inadequado do aluno é TDAH ou se o comportamento agitado do aluno provém do próprio comportamento do professor. Para que se considere um TDAH, os sintomas devem se manifestar em vários ambientes (escola, casa, viagens, e outros).

A abordagem interativa dos profissionais de saúde com a escola e com a família é imprescindível. Família e escola têm um papel fundamental para melhorar a autoestima e a saúde de um portador de Transtorno do Déficit de Atenção com Hiperatividade. Apoio, compreensão e aposta, são as melhores estratégias. Apoio nas novas perspectivas que um diagnóstico oferece. Compreensão de que a criança e ou aluno não tem exatamente falta de vontade freqüente (todos nós temos eventualmente), mas que tem dificuldades. E, finalmente, apostar e caminhar junto com o tratamento medicamentoso, psicológico e pedagógico.

\section{Referências bibliográficas}

CAMPOS, Lúcia Galvão do Amaral et al. Caracterização do desempenho de crianças com transtorno de Déficit de Atenção e Hiperatividade (TDAH) em provas operatórias. Revista Psicopedagogia ABPp. São Paulo, 1991, n.24, p. 218-228.

CONDEMARÍN, Mabel et al. Transtorno do Déficit de Atenção. Estratégias para o diagnostico e a intervenção psico-educativa. São Paulo: Planeta, 2006. 254p.

FERNÁNDEZ, Alicia. Os idiomas do aprendente: análise das modalidades ensinantes com famílias, escolas e meios de comunicação. Porto Alegre: Artmed, 2001. $223 p$.

ROHDE, Luís Augusto; BENCZIK, Edyleine. Transtorno do Déficit de Atenção e Hiperatividade: o que é? Como ajudar? Porto Alegre: Artmed, 1999. 92p.

SANTOS, Lucy. TDAH. Compreensão, Avaliação e Atuação: Uma visão geral sobre o TDAH. 2006. Disponível em: <http://www.autistas.org/tdah.html>. Acesso em: 29 maio 2015. 